\title{
A EXTRAÇÃO DE CAFEÍNA EM BEBIDAS ESTIMULANTES - UMA NOVA ABORDAGEM PARA UM EXPERIMENTO CLÁSSICO EM QUÍMICA ORGÂNICA
}

\author{
Eugênia Cristina Souza Brenelli \\ Departamento de Química Orgânica, Instituto de Química, Universidade Federal Fluminense, Outeiro de São João Batista, s/n, \\ 24020-150 Niterói - RJ
}

Recebido em 12/11/01; aceito em 23/9/02

\begin{abstract}
CAFFEINE EXTRACTION FROM STIMULATING BEVERAGES: A NEW APPROACH FOR A CLASSIC ORGANIC CHEMISTRY EXPERIMENT. Caffeine extraction procedures from water soluble and water insoluble materials for preparing stimulating beverages are described. Water soluble materials used were instant tea and coffee and water insoluble materials were, among others, guaraná powder and maté leaves. The extraction of caffeine from water soluble materials, especially instant tea, is more suitable for an organic chemistry teaching laboratory than the classic experiment using tea leaves, due to the economy of time and a larger amount of extracted caffeine. The procedure is time-saving and requires only a four-hour period. The experiments illustrate the extraction process as used in undergraduate organic chemistry laboratories.
\end{abstract}

Keywords: caffeine extraction; stimulant beverages; guarana.

\section{INTRODUÇÃO}

O isolamento de compostos orgânicos a partir de fontes naturais é um tipo de experimento muito empregado em disciplinas experimentais de graduação em química orgânica. A extração de cafeína das folhas de chá mate (Ilex paraguariensis) é um exemplo bastante popular em livros texto de química orgânica experimental ${ }^{1}$ e $\operatorname{artigos~}$ em revistas especializadas ${ }^{2-4}$. Esse experimento geralmente é empregado nas disciplinas iniciais de química orgânica, onde são apresentadas as principais técnicas de isolamento, purificação e caracterização de substâncias. O experimento alia a motivação do estudante, através da utilização de um produto de uso cotidiano, ao aprendizado de técnicas de extração com solventes e purificação de substâncias naturais, no caso a cafeína. Além disso, os reagentes empregados são de baixo custo e não tóxicos. Com o mesmo propósito, embora de forma menos abundante, a literatura cita a extração de cafeína a partir de outras fontes como, por exemplo, o café (Coffea arabica $)^{5}$ e o chá preto (Camellia sinensis) ${ }^{6}$. A erva mate (Ilex paraguariensis) e o guaraná (Paullinia cupana) ${ }^{7}$ também contêm cafeína, contudo, no melhor do nosso conhecimento, a utilização destes materiais com este propósito ainda não foi descrita na literatura.

Neste trabalho, descreve-se a extração de cafeína a partir de bebidas estimulantes utilizando-se dois métodos: um, para amostras solúveis em água, que pode ser aplicado em disciplinas de quatro horas de duração e outro, para amostras insolúveis em água, que requer dois períodos não consecutivos em disciplinas de quatro horas de duração.

\section{A CAFEÍNA}

A cafeína é um alcalóide (Figura 1), um composto contendo nitrogênio, que apresenta propriedades básicas. Ela pertence a uma classe de compostos de ocorrência natural chamada xantina. Possivelmente, as xantinas são os estimulantes mais antigos conhecidos sendo que, neste contexto, a cafeína é um dos mais potentes ${ }^{8}$.

e-mail: gqoecsb@vm.uff.br<smiles>Cn1c(=O)c2c(ncn2C)n(C)c1=O</smiles>

Figura 1. Fórmula estrutural da cafeína

Os principais efeitos fisiológicos ${ }^{9}$ da atuação da cafeína no organismo humano são o efeito estimulante, o efeito diurético e a dependência química. Entre outros efeitos, causa o aumento da taxa metabólica, o relaxamento da musculatura lisa dos brônquios, do trato biliar, do trato gastrintestinal e de partes do sistema vascular. Após cinco minutos do consumo, a cafeína pode ser detectada em todo o corpo humano, atingindo o seu máximo depois de 20-30 $\min ^{10}$. Ela é metabolizada no fígado e tem uma meia vida de cerca de 3-6 h, não acumulando no corpo. A ingestão de cafeína em excesso pode causar vários sintomas desagradáveis incluindo a irritabilidade, dores de cabeça, insônia, diarréia, palpitações do coração. A dose letal para uma pessoa adulta pesando $70 \mathrm{~kg}$ é cerca de $10 \mathrm{~g}$ o que é equivalente a se tomar 100 xícaras de café ou 200 latas de Coca-Cola ou ingerir $50 \mathrm{~kg}$ de chocolate $^{11}$.

\section{RESULTADOS E DISCUSSÃO}

A concentração de cafeína no chá ou café depende de vários fatores, incluindo a espécie da semente do café ou folha do chá, local de cultivo, granulações da amostra, etc. Estudos mostraram que, no caso do chá, a localização da folha na planta afeta o seu conteúdo de cafeína. Por este motivo, os valores relatados na literatura são variáveis. No caso do café e do chá, eles podem variar entre 2 a 4,6\% . O conteúdo de cafeína no caso do guaraná pode variar entre 3 a $6 \%{ }^{12}$.

O objetivo desse trabalho é o de apresentar metodologias adequadas a um curso de graduação em química orgânica, não se pretendendo fazer determinações quantitativas do conteúdo de cafeína de várias fontes, uma vez que existem metodologias mais adequadas para esta finalidade. 
A Tabela 1 e a Figura 2 apresentam os resultados obtidos utilizando-se dois métodos para a extração de cafeína de bebidas estimulantes. O método 1 é adequado para amostras solúveis em água e, o método 2, para amostras solúveis e insolúveis em água. Através dos dados tabelados, percebe-se claramente que, independentemente do método utilizado, as amostras que apresentaram um maior conteúdo de cafeína foram o café solúvel $(0,24$ g ou 2,4\%) e as folhas de chá preto $(0,21 \mathrm{~g}$ ou $2,1 \%)$, em seguida o café em pó e o pó de guaraná $(0,15 \mathrm{~g}$ cada ou $1,4 \%)$, depois a erva mate $(0,12 \mathrm{~g}$ ou $1,2 \%)$ e o mate solúvel $(0,10 \mathrm{~g}$ ou $0,99 \%)$ e, por último, as folhas de chá mate $(0,03$ g ou $0,29 \%$ ). Nas amostras de café e mate solúveis, é possível que o conteúdo de cafeína seja maior em função da ausência de resíduos de sementes, galhos e folhas que costumam estar presentes nas amostras de café em pó ou de chá mate. Segundo a referência utilizada para este estudo ${ }^{13}$, independentemente do material utilizado (sementes de café, café solúvel, folhas de chá mate e erva mate), o rendimento esperado de cafeína é cerca de $2 \%$. Vogt e colaboradores ${ }^{14}$, determinaram o conteúdo de cafeína no chá preto usando como técnica a cromatografia micelar eletrocinética, obtendo cerca de $2,4 \%$. Segundo os autores este é um valor típico para amostras de chá preto. Mitchell e colaboradores ${ }^{2}$, ao extraírem cafeína de saquinhos de chá mate obtiveram cerca de 0,2-0,4\% de cafeína purificada. Assim, os valores obtidos para o conteúdo de cafeína neste estudo, usandose vários materiais, são concordantes com os já descritos.

A Figura 2 também mostra que não há diferença significativa no conteúdo de cafeína extraída das amostras solúveis em água (café e mate solúvel) para as duas metodologias empregadas. Isto significa um ganho de tempo importante na aplicação do método 1, no caso de disciplinas em que se dispõe de períodos curtos para as práticas.

Embora a amostra de mate solúvel tenha apresentado um menor conteúdo de cafeína que o café solúvel, ela é uma alternativa bastante interessante em relação ao uso das folhas de chá mate, já que este apresentou o menor conteúdo de cafeína extraída entre todas as amostras e atualmente, como já dissemos, é um dos experimentos mais populares em química orgânica. Em relação às folhas de chá mate $(0,03 \mathrm{~g})$, a erva mate apresentou um conteúdo de cafeína bruta extraída $(0,12 \mathrm{~g})$ muito superior. A diferença entre a erva mate e o chá mate é que o último sofre um processo de queima (chá mate tostado, conforme a embalagem). Neste processo, é possível que haja alguma perda de cafeína em relação à erva mate. Caso a aplicação do método 1 em uma amostra de mate solúvel não fosse possível, uma melhor opção seria a utilização da erva mate ao invés das folhas de chá mate. A aplicação do método 1 permite que o estudante obtenha uma quantidade de amostra suficiente (sólido branco amarelado), para realizar
Extração de Cafeína de Bebidas Estimulantes

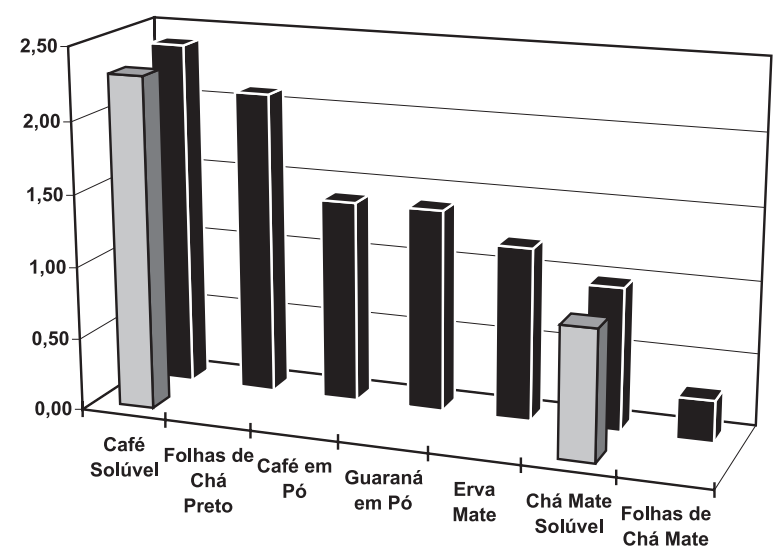

$\square \%$ de Cafeína Bruta pelo Método 1 \% de Cafeína Bruta pelo Método 2

Figura 2. Gráfico da \% de cafeína bruta extraída de bebidas estimulantes usando-se dois métodos

uma purificação, tendo a oportunidade de aprender técnicas básicas e muito usadas em química orgânica como a recristalização ${ }^{15}$, sublimação ${ }^{16}$ e a cromatografia em coluna ${ }^{17}$ podendo, em seguida, determinar o ponto de fusão da amostra pura $\left(238^{\circ} \mathrm{C}\right)^{7}$.

Uma quantidade maior de amostra também permite ao estudante a preparação de um derivado da cafeína ${ }^{18}$, o sal derivado do ácido salicílico, o qual apresenta ponto de fusão de $137{ }^{\circ} \mathrm{C}^{1}$ facilitando a caracterização da amostra obtida, como indicado no Esquema 1.

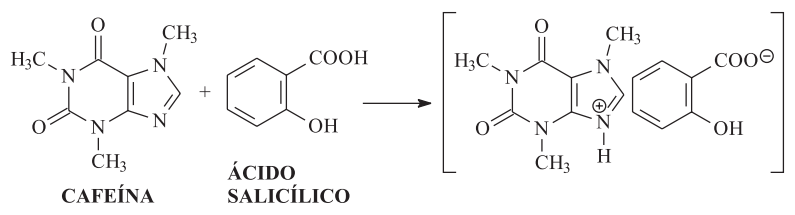

Esquema 1. Preparação do salicilato de cafeína

Finalizando, observa-se que tanto o café em pó quanto o guaraná em pó apresentaram o mesmo conteúdo de cafeína bruta extraída $(0,15 \mathrm{~g})$. Embora o café seja menos utilizado na literatura que as

Tabela 1. Resultados obtidos na extração de cafeína de várias bebidas estimulantes de amostras solúveis e não solúveis em água

\begin{tabular}{lcccc}
\hline Amostra & $\begin{array}{c}\text { Método de } \\
\text { Extração }^{\mathrm{h}}\end{array}$ & $\begin{array}{c}\text { Massa } \\
\text { Inicial/g }\end{array}$ & $\begin{array}{c}\text { Massa de Cafeína Bruta } \\
\text { Extraída/g }\end{array}$ & $\begin{array}{c}\text { Cafeína Bruta } \\
\text { Extraída/\% }\end{array}$ \\
\hline Café Solúvel $^{\mathrm{a}}$ & 1 & 10,20 & 0,23 & 2,3 \\
Mate Solúvel $^{\mathrm{b}}$ & 1 & 10,02 & 0,09 & 0,90 \\
Café Solúvel $^{\mathrm{a}}$ & 2 & 10,20 & 0,24 & 2,4 \\
Café em Póc $^{\text {Mate Solúvel }}$ & 2 & 10,75 & 0,15 & 1,4 \\
Folhas de Chá Mate $^{\mathrm{d}}$ & 2 & 10,15 & 0,10 & 0,99 \\
Erva Mate $^{\text {Folhas de Chá Preto }}$ & 2 & 10,17 & 0,03 & 0,12 \\
Pó de Guaranág & 2 & 10,27 & 0,21 & 1,2 \\
\hline
\end{tabular}

${ }^{\mathrm{a} C a f e ́ ~(C o f f e a ~ a r a b i c a) ~ d o ~ P o n t o ~ S o l u ́ v e l ~ G r a n u l a d o ~ T r a d i c i o n a l, ~}{ }^{\mathrm{b}}$ Mate (Ilex paraguariensis) Solúvel Matte Leão, ${ }^{\mathrm{c} C a f e ́ ~(C o f f e a ~ a r a b i c a) ~ d o ~}$ Ponto em Pó Extra Forte, ${ }^{\mathrm{d} C h a ́ ~ M a t e ~(I l e x ~ p a r a g u a r i e n s i s) ~ T o s t a d o ~ E x t r a ~ F o r t e ~ C a r r e f o u r, ~}{ }^{\circledR}$ Erva Mate (Ilex paraguariensis) Chimarrão Gaúcho, ${ }^{\mathrm{f} C h a ́ ~ P r e t o ~(C a m e l l i a ~ s i n e n s i s) ~ R o y a l ~ B l e n d, ~}{ }^{\mathrm{g} P o ́ ~ d e ~ G u a r a n a ́ ~(P a u l l i n i a ~ c u p a n a) ~ F o n t e ~ d e ~ J u v e n t u d e, ~}{ }^{\text {h} M e ́ t o d o ~} 1$ - Amostras solúveis em água, Método 2 - Amostras solúveis e insolúveis em água. 
folhas de chá mate para a extração de cafeína, neste contexto, no melhor do nosso conhecimento, o pó de guaraná não tem sido empregado, sendo que a quantidade de cafeína bruta extraída é uma quantidade apropriada para experimentos subseqüentes ao da sua extração, conforme exemplificamos acima. Adicionalmente, o pó de guaraná apresenta um forte apelo motivador ao estudante, como uma amostra do cotidiano.

\section{CONCLUSÕES}

O método descrito neste trabalho para a extração de cafeína de amostras solúveis em água, como o café e o mate solúvel, apresentou um conteúdo de cafeína similar ao método que emprega a utilização de um extrator de Soxhlet e permite a sua implementação em disciplinas que dispõem de períodos curtos de aula. Além do tempo mais curto, a amostra solúvel, principalmente no caso do chá mate, permite a obtenção de um conteúdo maior de cafeína do que a amostra oriunda das folhas possibilitando que, numa etapa posterior, possa ser feita a purificação e a caracterização da cafeína obtida. Comparativamente a outros métodos descritos na literatura e já citados anteriormente, este método apresenta como vantagens a utilização de reagentes de baixa toxicidade, o emprego de pequenas quantidades de amostra e reagentes e a geração de poucos resíduos.

Embora requeira um período extra de quatro horas de aula, a adoção do método que utiliza um extrator de Soxhlet permite a ampliação do tipo de amostras que podem ser utilizadas e que ainda não haviam sido descritas na literatura com este propósito, como o pó de guaraná e as folhas de erva mate. Adicionalmente, a aplicação deste método permite que os conceitos de extração contínua e descontínua possam ser abordados com o estudante, enfatizando-se as principais diferenças entre eles.

\section{PARTE EXPERIMENTAL}

\section{Método 1}

Procedimento para amostras solúveis em água ${ }^{19}$. Este procedimento foi adaptado de um procedimento descrito na literatura ${ }^{13} \mathrm{e}$ realizado como a seguir.

Em um béquer de $500 \mathrm{~mL}$, pesar $10 \mathrm{~g}$ de café ou mate instantâneo e dissolver em cerca de $125 \mathrm{~mL}$ de água quente. Deixar a solução esfriar um pouco e adicionar $100 \mathrm{~mL}$ de uma solução $10 \%$ em óxido de magnésio e agitar a mistura em banho-maria por cerca de 30 min. Isto faz com que os taninos formem sais insolúveis em água e precipitem da solução. Depois de decorrido o tempo necessário, retirar a mistura do banho-maria e deixar esfriar um pouco. Filtrar a suspensão a vácuo e adicionar, ao sobrenadante, cerca de $10 \mathrm{~mL}$ de uma solução de ácido sulfúrico $0,1 \mathrm{~mol} / \mathrm{L}$ para acidificar o meio (medir o pH com um papel indicador e, se necessário, adicionar mais ácido sulfúrico até o $\mathrm{pH}$ ficar próximo de 1). Em uma placa de aquecimento e agitação, concentrar o sobrenadante até a metade do seu volume original. Depois de frio, extrair o sobrenadante com 3 porções de $15 \mathrm{~mL}$ de diclorometano. Aos extratos orgânicos combinados, adicionar cerca de $8 \mathrm{~mL}$ de uma solução de hidróxido de potássio $0,1 \mathrm{~mol} / \mathrm{L}$. Isto remove parcialmente a coloração amarelada do extrato orgânico. Transferir a camada orgânica para um erlenmeyer e lavar a fase aquosa básica com duas porções de $5 \mathrm{~mL}$ de diclorometano. Combinar ambos os extratos orgânicos e secar com sulfato de sódio anidro. Filtrar e evaporar o diclorometano em um balão de $100 \mathrm{~mL}$ previamente tarado.

\section{Método 2}

Procedimento para amostras solúveis e não solúveis em água ${ }^{20}$. Utilizando-se um extrator de Soxhlet, realizou-se o procedimento já descrito na literatura ${ }^{13}$ conforme indicado a seguir.

Pesar cerca de $10 \mathrm{~g}$ de amostra em um cartucho para Soxhlet e, caso isto não seja possível, montar um cartucho com papel de filtro. Utilizar um balão de $250 \mathrm{~mL}$ como reservatório e adicionar $150 \mathrm{~mL}$ de etanol juntamente com algumas pedras de ebulição. Inserir o cartucho com a amostra na câmara do extrator e montar o conjunto. Usar uma manta de aquecimento para refluxar a mistura por duas horas ${ }^{21}$. Esperar o extrato esfriar antes de adicionar $100 \mathrm{~mL}$ de uma solução de óxido de magnésio a 10\%. Evaporar o etanol em um evaporador rotativo e transferir a pasta resultante para um béquer de $500 \mathrm{~mL}$ com o auxílio de $125 \mathrm{~mL}$ de água destilada. Colocar esta mistura em um banho-maria e deixar em ebulição por cerca de 30 min. O procedimento restante é idêntico ao descrito acima para o método 1 .

\section{AGRADECIMENTOS}

Aos estudantes da disciplina de Química Orgânica I Experimental que testaram estes experimentos, aos revisores pelas valiosas sugestões e ao Prof. M. C. de Souza (IQ-UFF), pela revisão crítica deste texto.

\section{REFERÊNCIAS E NOTAS}

1. Pavia, D. L.; Lampman, G. M.; Kriz, G. S.; Engel, R. G.; Introduction to Organic Laboratory Techniques: Small Sacale Approach, Saunders College Publishing: Forth Worth, 1998, p. 71.

2. Mitchell, R. H.; Scott, W. A.; West, P. R.; J. Chem. Educ. 1974, 51, 69.

3. Murray, S. D.; Hansen, P. J.; J. Chem. Educ. 1995, 72, 851.

4. Hampp, A.; J. Chem. Educ. 1996, 73, 1172.

5. O'Connor, R.; J. Chem. Educ. 1965, 42, 492 .

6. Onami, T.; Kanazawa, H.; J. Chem. Educ. 1996, 73, 556.

7. The Merck Index $11^{\text {th }}$ Edition; Budavari, S., ed.; Merck \& Co., Inc.: New Jersey, 1989, p. 1635.

8. Ikan, R.; Natural Products: A Laboratory Guide, Harcourt Brace Jovanovich Publishers: New York, 1991, p. 226.

9. Faust, C. B.; Educ. Chem. 1993, 30, 149.

10. Cotton, S.; Educ. Chem. 2000, 37, 34.

11. Ottewill, G.; Educ. Chem. 1999, 36, 4

12. Mazzafera, P.; Rev. Bras. Fisiol. Veg. 1994, 6, 149.

13. Adam, D. J; Mainwaring, J.; Quigley, M. N.; J. Chem. Educ. 1996, 73, 1171.

14. Vogt, C.; Conradi, S.; Rohde, E.; J. Chem. Educ. 1997, 74, 1126.

15. Moye, A. L.; J. Chem. Educ. 1972, 49, 194.

16. Laswick, J. A.; Laswick, P. H.; J. Chem. Educ. 1972, 49, 708.

17. Taber, D. F.; Hoerner, R. S.; J. Chem. Educ. 1991, 68, 73.

18. Misturar em um erlenmeyer de $50 \mathrm{~mL} 26 \mathrm{mg}$ de cafeína, $19 \mathrm{mg}$ de ácido salicílico e $3 \mathrm{~mL}$ de tolueno. Agitar a mistura em banho-maria até a dissolução completa do sólido. Em seguida, retirar do banho e gotejar éter de petróleo de alto ponto de ebulição (fração $65-110^{\circ} \mathrm{C}$ ) até a solução turvar. Depois de filtrar o sólido e lavar bem com o éter de petróleo obtémse $39 \mathrm{mg}$ de salicilato de cafeína com ponto de fusão não corrigido entre 134- $136^{\circ} \mathrm{C}$ (lit. ${ }^{1} 137{ }^{\circ} \mathrm{C}$ ).

19. O experimento para a extração de cafeína de amostras solúveis em água requer um período de $4 \mathrm{~h}$ de aula e a purificação e caracterização da cafeína extraída requerem um período adicional de $4 \mathrm{~h}$.

20. O experimento para amostras solúveis e não solúveis utilizando-se um extrator de Soxhlet requer dois períodos não consecutivos de 4 h de aula; para a extração e para a purificação e caracterização da cafeína extraída é necessário um período adicional de $4 \mathrm{~h}$.

21. Se necessário pode-se interromper o procedimento neste ponto e continuar no próximo período. 